\title{
Genetic variation affecting DNA methylation and the human imprinting disorder, Beckwith-Wiedemann syndrome
}

Vinod Dagar ${ }^{1}$, Wendy Hutchison², Andrea Muscat ${ }^{3}$, Anita Krishnan ${ }^{4}$, David Hoke ${ }^{5}$, Ashley Buckle ${ }^{5}$, Priscillia Siswara², David J. Amor ${ }^{1,6}$, Jeffrey Mann ${ }^{7}$, Jason Pinner ${ }^{8}$, Alison Colley ${ }^{9}$, Meredith Wilson ${ }^{10}$, Rani Sachdev ${ }^{11}$,

George McGillivray ${ }^{6}$, Matthew Edwards ${ }^{12}$, Edwin Kirk ${ }^{11}$, Felicity Collins ${ }^{10}$, Kristi Jones ${ }^{10,13}$, Juliet Taylor ${ }^{14}$, lan Hayes ${ }^{14}$, Elizabeth Thompson ${ }^{15,16}$, Christopher Barnett ${ }^{15}$, Eric Haan ${ }^{15}$, Mary-Louise Freckmann ${ }^{17}$, Anne Turner ${ }^{11,18}$,

Susan White ${ }^{6}$, Ben Kamien ${ }^{19}$, Alan Ma ${ }^{10}$, Fiona Mackenzie ${ }^{20}$, Gareth Baynam ${ }^{20}$, Cathy Kiraly-Borri ${ }^{20}$, Michael Field ${ }^{19}$, Tracey Dudding-Byth ${ }^{19,21}$ and Elizabeth M. Algar ${ }^{1,2,22,23^{*}}$ (D)

\begin{abstract}
Background: Beckwith-Wiedemann syndrome (BWS) is an imprinting disorder with a population frequency of approximately 1 in 10,000. The most common epigenetic defect in BWS is a loss of methylation (LOM) at the 11 p15.5 imprinting centre, KCNQ1OT1 TSS-DMR, and affects 50\% of cases. We hypothesised that genetic factors linked to folate metabolism may play a role in BWS predisposition via effects on methylation maintenance at KCNQ1OT1 TSS-DMR.

Results: Single nucleotide variants (SNVs) in the folate pathway affecting methylenetetrahydrofolate reductase (MTHFR), methionine synthase reductase (MTRR), 5-methyltetrahydrofolate-homocysteine S-methyltransferase (MTR), cystathionine beta-synthase (CBS) and methionine adenosyltransferase (MAT1A) were examined in 55 BWS patients with KCNQ1OT1 TSS-DMR LOM and in 100 unaffected cases. MTHFR rs 1801133: C>T was more prevalent in BWS with KCNQ1OT1 TSS-DMR LOM ( $p<0.017)$; however, the relationship was not significant when the Bonferroni correction for multiple testing was applied (significance, $p=0.0036$ ). None of the remaining 13 SNVs were significantly different in the two populations tested. The DNMT1 locus was screened in 53 BWS cases, and three rare missense variants were identified in each of three patients: rs138841970: C>T, rs150331990: A>G and rs757460628: G>A encoding NP_001124295 p.Arg136Cys, p. His1118Arg and p.Arg1223His, respectively. These variants have population frequencies of less than 1 in 1000 and were absent from 100 control cases. Functional characterization using a hemimethylated DNA trapping assay revealed a reduced methyltransferase activity relative to wild-type DNMT1 for each variant ranging from 40 to $70 \%$ reduction in activity.
\end{abstract}

Conclusions: This study is the first to examine folate pathway genetics in BWS and to identify rare DNMT1 missense variants in affected individuals. Our data suggests that reduced DNMT1 activity could affect maintenance of methylation at KCNQ10T1 TSS-DMR in some cases of BWS, possibly via a maternal effect in the early embryo. Larger cohort studies are warranted to further interrogate the relationship between impaired MTHFR enzymatic activity attributable to MTHFR rs1801133: C>T, dietary folate intake and BWS.

Keywords: DNA methyltransferase 1, Beckwith-Wiedemann syndrome, One-carbon pathway, Methylation

\footnotetext{
*Correspondence: elizabeth.algar@monash.edu

'Department of Paediatrics, University of Melbourne, Parkville 3052, Australia

${ }^{2}$ Pathology, Monash Health, Clayton 3168, Australia

Full list of author information is available at the end of the article
}

(c) The Author(s). 2018 Open Access This article is distributed under the terms of the Creative Commons Attribution 4.0 International License (http://creativecommons.org/licenses/by/4.0/), which permits unrestricted use, distribution, and reproduction in any medium, provided you give appropriate credit to the original author(s) and the source, provide a link to the Creative Commons license, and indicate if changes were made. The Creative Commons Public Domain Dedication waiver (http://creativecommons.org/publicdomain/zero/1.0/) applies to the data made available in this article, unless otherwise stated. 


\section{Background}

The human imprinting disorder Beckwith-Wiedemann syndrome (BWS) (OMIM 130650) is characterised by overgrowth in the prenatal and postnatal period, macroglossia, umbilical hernia or exomphalos, neonatal hypoglycaemia, ear lobe creases and pits, nevi flammei, hemihyperplasia and organomegaly, particularly of the kidney, liver and pancreas. One of its more serious complications is an increased predisposition to cancer in early childhood with tumour risk segregating with distinct genetic and epigenetic subtypes (reviewed in [1-4]).

The majority of the affected children have an isolated epigenetic abnormality at the $11 \mathrm{p} 15.5$ imprinting centre 2 (IC2), known as KCNQ1OT1 TSS-DMR, the location of the KCNQ1OT1/CDKN1C locus. Fifty percent of all children with features of BWS have either mosaic or complete loss of methylation (LOM) within the KCNQ1OT1 promoter and impaired expression of maternal CDKN1C, a critical regulator of growth during early development $[5$, 6]. For the majority of BWS cases with KCNQ1OT1 TSS-DMR imprinting disruption, the aetiology is unknown and the phenotype arises without any evidence of heritability. Rare cases have been reported with imprinting defects in KCNQ1OT1 TSS-DMR associated with inherited recessive mutations affecting NLRP2 on 19q13.42 [7], and more recently, maternal effect missense and truncating variants in other NLRP loci, including NLRP5 and NLRP7, were reported in the mothers of offspring with multi-locus imprinting disruption (MLID) that included loss of methylation at KCNQ1OT1 TSS-DMR [8, 9]. MLID cases with methylation loss at KCNQ1OT1 TSS-DMR frequently had characteristics of BWS. Animal studies have shown that defective methylation is set in the gametes or during the first cell divisions of the embryo, and genetic modifiers and environmental factors influence this process [10]. Indeed, in BWS, the increased incidence of BWS cases with KCNQ1OT1 TSS-DMR LOM after assisted reproduction (ART) points to the involvement of environmental factors that perturb methylation at KCNQ1OT1 TSS-DMR or alternatively suggest a link between therapeutic interventions for female infertility and defective methylation [11-15].

The one-carbon pathway is the major metabolic pathway through which dietary folate is converted to methyl donor groups that subsequently methylate DNA via catalysis of the universal methyl donor $S$-adenosyl-methionine in the presence of DNA methyltransferase 1 (DNMT1). The key enzymes of this pathway include methylenetetrahydrofolate reductase (MTHFR), methionine synthase reductase (MTRR), 5-methyltetrahydrofolate-homocysteine $S$-methyltransferase (MTR), cystathionine beta-synthase (CBS) and methionine adenosyltransferase (MAT1A), and the associated effects of genetic variants with impaired enzyme activity have been documented in several studies. A common SNV (previously commonly known as c.677C $>$ T) in MTHFR, rs1801133: C>T, NP_005948.3: p.Ala222Val, increases protein thermolability [16] and has been linked to vascular thromobosis, hyperhomocysteinaemia and global hypomethylation in a setting of dietary folate depletion ([17-20]. A second MTHFR SNV, rs1801131: A>C, NP_005948.3: p.Gln429Ala, is linked to DNA hypomethylation, independently of folate availability and acts synergistically with rs1801133 to reduce MTHFR activity [21, 22]. MTR catalyses the remethylation of homocysteine to methionine and SNV rs1805087: A>G, NP_000245.2: p.Asp919Gly alters the helix structure in the substrate binding domain leading to impaired methionine biosynthesis and reduced methyl donor availability [23-25]. MTRR rs1801394: A>G, NP_002445.2 p.Ile22Met, acts synergistically with homozygous MTHFR rs1801133: C>T, NP_005948.3: p.Ala222Val, in the presence of low folate and/or vitamin B12 status [26].

The isoforms of Dnmt1 (Dnmt1o and Dnmt1s) play a critical role in the maintenance of DNA methylation at imprinted regions during pre-implantation mammalian development [27]. The absence of $118 \mathrm{~N}$ terminal amino acids allows Dnmt1o protein to accumulate to high levels in non-dividing growing oocytes [28], and expression is maintained in pre-implantation embryos in the morula and blastocyst. Howell et al. 2001 showed that Dnmt1o, while not essential for imprint establishment in oocytes, was required for the maintenance of methylation at imprinted loci, and heterozygous offspring of Dnmt1o-null mothers exhibited imprinting defects. The functions of Dnmt1o and Dnmt1 are interchangeable as Dnmt1 is itself able to maintain methylation during pre-implantation development [29, 30], and Dnmt1o can rescue Dnmt1-/- ES cells [31]. However, although these studies implicate DNMT1 in imprinting disorders, it has not previously been examined in the context of BWS or MLID.

In this study, we investigated the genetics of folate metabolism and maintenance of DNA methylation in cases of BWS with loss of methylation at KCNQ1OT1 TSS-DMR. This included an analysis of SNVs in MTHFR, MTRR, MTR, MAT1A and CBS predicted to alter the function and a full mutation screen of DNMT1. While a statistically significant association between deleterious SNVs in folate pathway genes could not be conclusively demonstrated, we identified three patients with rare missense amino acid substitutions in DNMT1 that are represented in dbSNP at a frequency of $<0.001$. Functional characterization of these variants showed a significant reduction in complex formation with hemimethylated DNA, consistent with impaired DNMT1 activity. This is the first study examining the folate pathway and the major human methyltransferase, DNMT1, in the most common epigenetic subtype of BWS. 


\section{Results}

Analysis of MTHFR, MTRR, MTR, MAT1A and CBS in BWS cases with KCNQ10T1 TSS-DMR LOM

The one-carbon pathway of folate metabolism is shown in Fig. 1. Coding SNVs in MTHFR, MTRR and MTR generating missense amino acid substitutions and for which previous evidence of impaired or altered enzyme function had been demonstrated in other studies were selected for investigation in the BWS study population (55 cases) and in a matched local control population (100 cases). The enzymes MAT1A and CBS were also included because rare coding SNVs were identified in genome databases with damaging polyphen scores and predicted structural effects.

All gene SNVs interrogated in the study are shown in Table 1.

Fifty-five unrelated cases with clinical features of BWS were assessed as having either complete or partial LOM at KCNQ1OT1 TSS-DMR. Ten of these 55 cases had multi-locus imprinting disruption (MLID) involving losses of methylation at additional imprinting domains including MEST, PLAGL1, GRB10, NESPAS and PEG3 (Additional file 1: Table S1). A total of 11 cases had been conceived using assisted reproductive technologies (ART). Specimens were screened using HRM across selected one-carbon pathway SNVs, and those with shifted melt profiles were sequenced. Specific reaction conditions are shown in Additional file 1: Tables S2 and S3. The significance of minor allele SNV frequencies in the BWS study population for each gene was calculated using the chi-squared analysis relative to the frequencies determined in 100 control DNA specimens from the cord blood.

The MTHFR rs1801133 minor allele is more prevalent in BWS with KCNQ1OT1 TSS-DMR LOM.
Table 2 shows SNV frequencies in BWS patients with KCNQ1OT1 TSS-DMR LOM, including those with MLID, compared to controls and frequencies in dbSNP147. One SNV of 14 screened, MTHFR rs1801133: C>T, was significantly different when compared to the local control population with a $p$ value of 0.0167 derived using a $2 \times 2$ contingency table. There were $43 \mathrm{~T}$ alleles in a total of 110 in the BWS subgroup compared to $52 \mathrm{~T}$ alleles in a total of 200 alleles in the control group. MAT1A and CBS minor allele frequencies were too low in both populations for meaningful statistical analysis to be done. After correcting for multiple testing of each of the 14 one-carbon pathway SNVs examined, the Bonferroni significance value was 0.0036 (0.05/14). The $p$ value for MTHFR rs1801133: C>T at 0.0167 was no longer significant when this more stringent statistical test was applied to the data. Hence, although MTHFR rs1801133: $\mathrm{C}>\mathrm{T}$ appears to be more prevalent in the BWS population, this finding is not statistically significant when adjustment for multiple testing is applied.

\section{Rare variants of DNMT1 are present in some BWS cases with KCNQ10T1 TSS-DMR LOM}

Dnmt1 and Dnmt1o proteins play a central role in the maintenance of DNA methylation during pre-implantation embryonic development, and DNMT1 is the major enzyme in the folate pathway responsible for the catalysis of $S$-adenosyl methionine, providing methyl groups for methylation of DNA. Hayward et al. [32] defined the location of human DNMT1o from sequence derived from EST BE537788. Primers were designed to this region (hg19 GRCh37 chr19: 10311482-10311816) and to the entire coding region of DNMT1 (NM_001130823.1, representing the longest transcript). Variants affecting the coding regions of DNMT1o and DNMT1 were screened by HRM and sequenced to

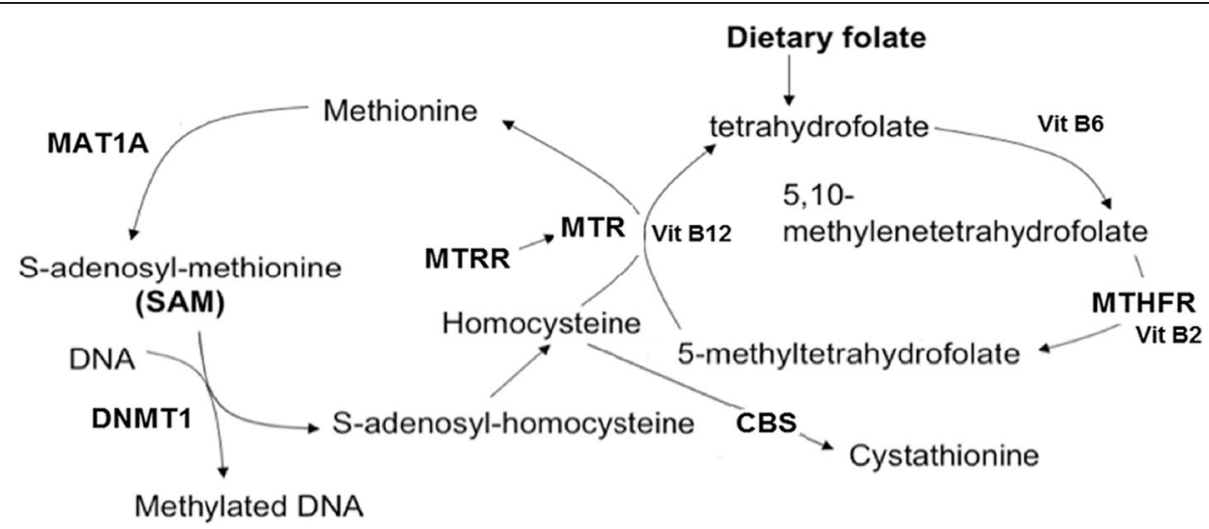

Fig. 1 The one-carbon pathway responsible for the conversion of dietary folate to methyl donor groups. The critical enzymes in the pathway examined in this study are shown in bold. MTHFR is primarily responsible for the conversion of tetrahydrofolate to methylene-tetrahydrofolate. MTRR and MTR work together to catalyse the conversion of homocysteine to methionine in the presence of the cofactor vitamin B12 and zinc, enabling the movement of the methyl group from methylene-tetrahydrofolate and recycling of tetrahydrofolate. CBS converts homocysteine in the presence of vitamin B6 to cystathione and MAT1A is responsible for converting methionine to S-adenosy-methionine (SAM), the ultimate methyl donor for DNA via catalysis by DNA methyltransferase 
Table 1 SNVs interrogated in BWS patients with loss of methylation at KCNQ1OT1 TSS-DMR

\begin{tabular}{|c|c|c|c|c|}
\hline Gene & SNV_1 ID & SNV_2 ID & SNV_3 ID & SNV_4 ID \\
\hline \multirow[t]{4}{*}{ MTHFR } & 677C>T Rs 1801133: C>T & Rs 1801131: A>C & Rs 2274976: G>A & \\
\hline & NM_005957.4: c.665C>T & NM_005957.4: c.1286A>C & NM_005957.4:c.1781G>A & \\
\hline & NP_005948.3 p.Ala222Val & NP_005948.3 p.Gln429Ala & NP_005948.3 p.Arg594Gln & \\
\hline & $A=0.24$ & $G=0.24$ & $T=0.075$ & \\
\hline \multirow[t]{4}{*}{ MTRR } & Rs 1801394: A>G & Rs 2287780: C>T & Rs 10380: C>T & \\
\hline & NM_002454.2: c.66A>G & NM_002454.2: c.1243C>T & NM_024010.2: c.1864C>T & \\
\hline & NP_002445.2 p.lle22Met & NP_002445.2 p.Arg415Cys & NP_076915.2 p.His622Tyr & \\
\hline & $\mathrm{G}=0.36 \mathrm{GMAF}, 0.47$ ClinVar, 0.45 EXAC & $T=0.0679$ & $T=0.219$ & \\
\hline \multirow[t]{4}{*}{ MAT1A } & Rs 114494303: G>A & Rs 72558181: G>A & Rs 112848063: A>G & Rs 116659053: G>A \\
\hline & NM_00429.2: c.530G>A & NM_00429.2: c.791G>A & NM_00429.2: c.1061A>G & NM_00429.2: c.1066G>A \\
\hline & NP_00420.1 p.Arg177Gln & NP_00420.1 p.Arg264His & NP_00420.1 p.Asp354Gly & NP_00420.1 p.Arg356Trp \\
\hline & $A=0.0002$ & $A=0.000009$ & & $A=0.0002$ \\
\hline \multirow[t]{4}{*}{ MTR } & Rs 1805087: $A>G$ & & & \\
\hline & NM_000254.2: c.2756A>G, & & & \\
\hline & NP_000245.2 p.Asp919Gly & & & \\
\hline & $G=0.218$ & & & \\
\hline \multirow[t]{5}{*}{ CBS } & Rs 17849313: G>C & Rs 117687681: C>T & Rs 11700812: G>A/C & \\
\hline & NM_001178009.1: c.205G>C & NM_001178009.1: c.1105C>T & NM_000071.2: C.1106G>A, G>C & \\
\hline & NP_000062.1 p.Ala69Pro & NP_000062.1 p.Arg369Cys & NP_001171479.1 p.Arg369His, & \\
\hline & & $A=0.0012$ & NP_001171479.1 p.Arg369Pro. & \\
\hline & & & $\mathrm{T} / \mathrm{G}=0.00003$ & \\
\hline
\end{tabular}

Allele frequency data was obtained from dbSNP147 or other sources as indicated. Minor allele nucleotides on the forward genomic strand are shown. Where the alternate allele frequency is not shown, the SNV frequency is unknown. The MTHFR variant commonly referred to as c.677C $>$ T is MTHFR: NM_005957.4 c.665C $>$ T in HGVS format. Nucleotide numbering uses +1 as the $A$ of the ATG translation initiation codon

Table 2 Table showing one carbon pathway enzyme allele frequencies in 55 BWS and 100 control specimens and their significance values

\begin{tabular}{|c|c|c|c|c|c|}
\hline Gene & SNV & BWS MAF 110 alleles & Local control MAF 200 alleles & $p$ value BWS versus local controls & Global control MAF \\
\hline \multirow[t]{3}{*}{ MTHFR } & Rs1801133: C>T & 0.391 & 0.260 & 0.0167 & 0.24 \\
\hline & Rs1801131: A>C & 0.309 & 0.400 & 0.0516 & 0.2494 \\
\hline & Rs2274976: G>A & 0.045 & 0.060 & 0.6606 & 0.075 \\
\hline \multirow[t]{3}{*}{ MTRR } & Rs1801394: A>G & 0.560 & 0.490 & 0.214 & $0.46^{*}$ \\
\hline & Rs2287780: C>T & 0.0833 & 0.035 & 0.068 & 0.076 \\
\hline & Rs10380: C>T & 0.1204 & 0.090 & 0.397 & 0.174 \\
\hline \multirow[t]{4}{*}{ MAT1A } & Rs1 14494303: G>A & 0.01 & 0.00 & NS & 0.0002 \\
\hline & Rs72558181: G>A & 0.01 & 0.00 & NS & 0.000009 \\
\hline & Rs112848063: $A>G$ & 0.00 & 0.00 & NS & NA \\
\hline & Rs1 16659053: G>A & 0.00 & 0.00 & NS & 0.0002 \\
\hline MTR & Rs1805087: $A>G$ & 0.2091 & 0.220 & 0.981 & 0.218 \\
\hline \multirow[t]{3}{*}{ CBS } & Rs17849313: G>C & 0.000 & 0.00 & NS & NA \\
\hline & Rs117687681: C>T & 0.010 & 0.00 & NS & NA \\
\hline & Rs1 1700812: G>A/C & 0.000 & 0.00 & NS & NA \\
\hline
\end{tabular}

Global allele frequencies were derived from dbSNP147. $p$ values were derived from chi-squared analysis with one degree of freedom

$p$ values of significance $(<0.05)$ are in italics

MAF minor allele frequency, NS not significant, NA data not available

*The minor allele frequency was calculated from the mean MAF in EXAc (0.452) and Clinvar (0.47) 


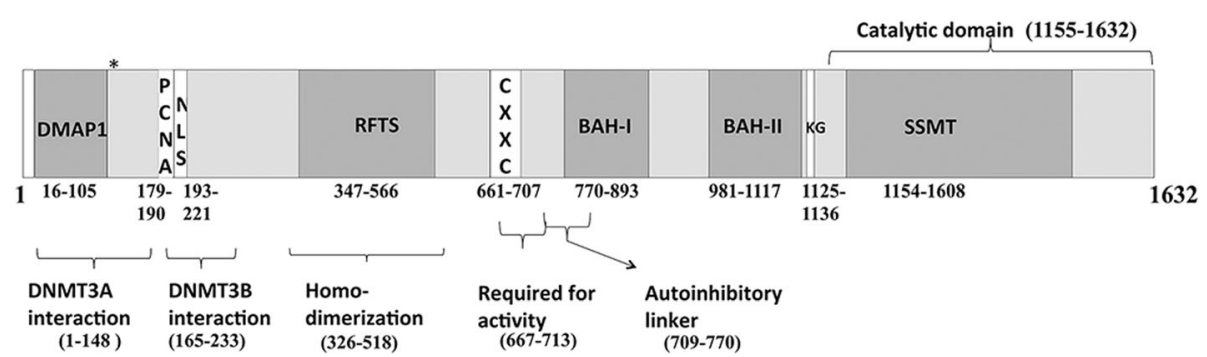

Fig. 2 Structure of DNMT1 compiled from information in NCBI for NP_001124295.1 [45]. Replication fork targeting sequence (RFTS), nuclear localization signal (NLS), bromo-adjacent homology (BAH) domain, site-specific DNA cytosine methylase activity (SSMT), zinc finger domain (CXXC). The "**" symbol represents the translation start of the shorter DNMT1o form at amino acid 119. Conserved domains are DMAP1, RFTS, CXXC, BAH, KG linker sequence and SSMT. Numbers represent amino acid numbering

confirm their identity. A schematic of DNMT1 and DNMT1o protein structure is shown in Fig. 2.

Fifty-three of the 55 BWS cases with KCNQ1OT1 TSS-DMR LOM were tested for SNVs in the coding regions of DNMT1. A total of 17 DNMT1 SNVs were identified. No SNVs were identified in the sequence exon 1o, unique to DNMT1 and upstream of the DNMT1o ATG. All of the DNMT1 SNVs identified have been reported in dbSNP147. This database represents compiled variant data from 37 different genomic databases. Five substitutions were synonymous coding SNVs, six were located within the intronic sequence flanking exons and not predicted to affect splicing and one rare variant rs772176328: $\mathrm{C}>\mathrm{T}$, flanking exon 34 (NC_000019.10:g.10139820G >A (NM_001318731.1: c.3444-3C $>$ T) had the potential to affect splicing but was not located within a canonical splice acceptor site. Five substitutions were missense variants with codon changes, four of which affected single patients only. Filtering of the missense DNMT1 variants identified three with allele frequencies of less than 1 in 1000 making them potentially interesting candidates for a disorder with a population frequency of approximately 1 in 10,000 [33]. These were DNMT1 SNVs rs138841970: C>T, rs150331990: $A>G$ and rs757460628: G>A encoding NP_001124295 p.Arg136Cys, p.His1118Arg and p.Arg1223His, respectively. Sequence traces are shown in Additional file 2: Figure S1. All missense variants identified and their allele frequencies are described in Table 3. All were heterozygous.

All five missense variants identified, including the three rare missense variants, are predicted to have a moderate effect on protein function according to integrated analysis in Variant Effect Predictor (http://asia.ensembl.org/Tools/ VEP). The variant, rs772176328: $\mathrm{C}>\mathrm{T}$, associated with a splice acceptor site, but not directly affecting a canonical base, was predicted to have a low impact on DNMT1 function. Amino acids Arg69 and Ile327 are not conserved in mouse, dog and some primates, and variants affecting these amino acid positions occur in control populations at frequencies of greater than 1 in 112 and 1 in 10, respectively, hence ruling them out as being significant in BWS. In contrast, Arg136 is conserved in all species expect dog, His1118 is conserved in all species except lamprey and Arg1223 is conserved in all species except mouse where it is leucine.

\section{Rare variants of DNMT1 have reduced methyltransferase activity}

To directly examine the functional impact of the three rare DNMT1 missense variants, GFP-tagged DNMT1 recombinant proteins were generated and purified from Hela cells (Fig. 3 a, b).

Single nucleotide substitutions within DNMT1 were inserted using site-directed mutagenesis (Additional file 2:

Table 3 Missense DNMT1 variants identified in BWS cases with LOM at KCNQ1OT1 TSS-DMR

\begin{tabular}{|c|c|c|c|c|c|c|c|}
\hline SNV ID & $\begin{array}{l}\text { Base change } \\
\text { NM_001130823.1 }\end{array}$ & $\begin{array}{l}\text { AA change } \\
\text { NP_001124295 }\end{array}$ & $\begin{array}{l}\text { Location } \\
\text { NM_001130823.1 }\end{array}$ & $\begin{array}{l}\text { Ch37/Hg19 } \\
\text { location }\end{array}$ & $\begin{array}{l}\text { BWS } \\
\text { VAF }\end{array}$ & $\begin{array}{l}\text { dbSNP147 } \\
\text { VAF }\end{array}$ & VEP \\
\hline $\begin{array}{l}\text { Rs } \\
61750053\end{array}$ & c. $206 \mathrm{G}>\mathrm{A}$ & p.Arg69His & Exon $3 / 41$ & Chr19:10291473 & 0.009 & 0.0089 & Moderate \\
\hline Rs 2228612 & c. $.979 A>G$ & p.lle327Val & Exon 13/41 & Chr19:10273372 & 0.11 & 0.135 & Moderate \\
\hline $\begin{array}{l}\text { Rs } \\
138841970\end{array}$ & $c .406 C>T$ & p.Arg136Cys & Exon 4/41 & Chr19:10291065 & 0.009 & 0.00028 & Moderate \\
\hline $\begin{array}{l}\text { Rs } \\
150331990\end{array}$ & c. $3353 A>G$ & p.His1118Arg & Exon 31/41 & Chr19:10251822 & 0.009 & 0.00001 & Moderate \\
\hline $\begin{array}{l}\text { Rs } \\
757460628\end{array}$ & c. $3668 \mathrm{G}>\mathrm{A}$ & p.Arg1223His & Exon 33/41 & Chr19:10250860 & 0.009 & 0.00002 & Moderate \\
\hline
\end{tabular}

Variant allele frequencies were derived from dbSNP147. The variant effect predictor (VEP) tool was used to ascertain effects on protein function. $V A F$ variant allele frequency 

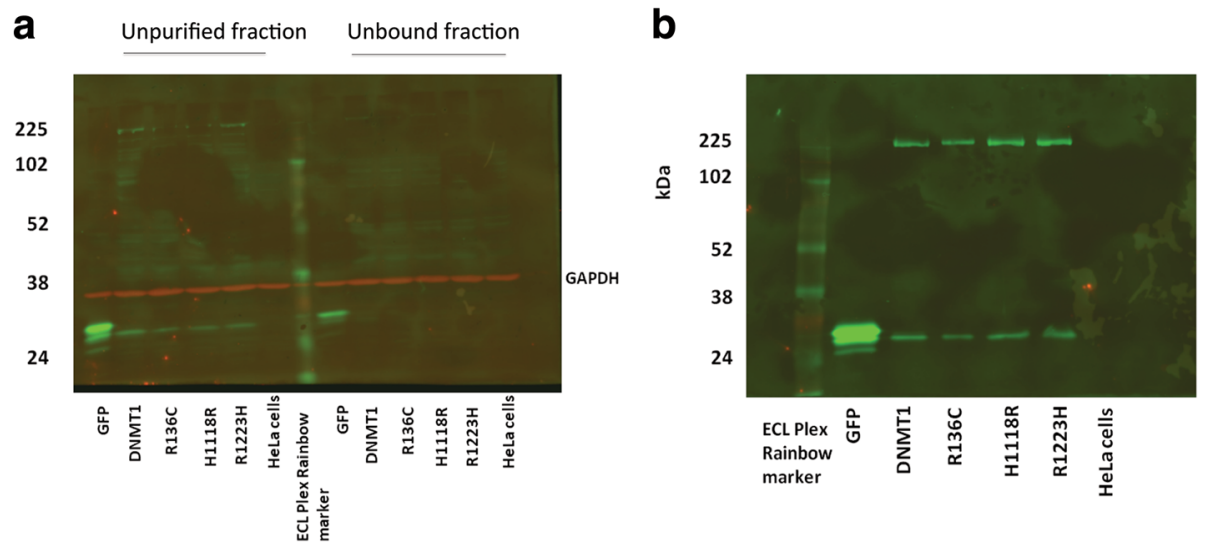

Fig. 3 CyDye fluorescent Western blots. a HeLa cell protein lysates present in unpurified and unbound lysate fractions probed with primary antibodies anti-GFP and anti-GAPDH and with secondary antibodies goat-anti-rabbit lgG Cy5 and goat-anti-mouse lgG Cy3. b Purified GFP-tagged DNMT1 protein (DNMT1 $225 \mathrm{kDa}$ ) and GFP (27 KDa) and DNMT1 variants generated by site-directed mutagenesis. The GFP bands in the fusion protein lanes in (b) likely represent cleavage products of the purified fusion protein

Figure S2). Wild-type and DNMT1 mutant fusion proteins were expressed exclusively in the nucleus of Hela cells (Additional file 2: Figure S3). The functional impact of the rare missense variants on DNMT1 enzymatic activity was examined in a trapping assay previously described by Frauer and Leonhardt (2009) in which substrate is irreversibly covalently bound to DNMT1. The degree of binding is a surrogate for DNMT1 enzymatic activity as it measures the irreversible covalent enzyme-DNA complex formation as the first step of the DNA methylation reaction. Trapping activity measured relative to that of the wild-type DNMT1 protein is shown in Fig. 4.

The data in Fig. 4 shows that each missense variant exhibited reduced substrate trapping activity when compared with wild-type DNMT1 suggesting that these variants are less efficient at maintaining DNA methylation. Interestingly, each BWS case with these variants exhibited a complete LOM at KCNQ1OT1 TSS-DMR as opposed to partial or mosaic LOM the latter being a common finding in the majority of cases. The variants are predicted to affect the function of the $\mathrm{N}$ terminally truncated DNMT1 form, DNMT1o, in addition to DNMT1, although functional effects on DNMT1o were not examined directly. Information on these DNMT1 missense variants has been submitted to Clinvar and assigned accession numbers 3026604, 3027874 and 3028253.

It is interesting to note that DNMT1 NM_001130823.1: c.406C > T, NP_001124295p.Arg136Cys, is located in the $\mathrm{N}$-terminal domain and shows the least reduction in trapping activity whereas DNMT1 NM_001130823.1: c.3668G >A, NP_001124295 p.Arg1223His, is located in the $\mathrm{C}$-terminal catalytic domain very close to the catalytic site at p.Cys 1242 and shows the maximum reduction in trapping activity compared to wild-type DNMT1 protein. The variant, DNMT1 NM_001130823.1: c.3353 A>G, NP_001124295 p.His1118Arg, is located adjacent to the glycine-lysine repeat region linking the BAH2 domain to the C-terminal catalytic domain and has trapping ability of approximately $50 \%$ compared to the wild-type protein.

\section{Patient characteristics associated with variant DNMT1}

Clinical features of patients with functionally impaired DNMT1 variants of very low population frequency are shown in Table 4. BWS has a broad clinical presentation, and no particular feature could be ascribed to this subgroup. All cases had methylation values at KCNQ1OT1 TSS-DMR of 0.00 indicative of a complete loss of methylation in the blood. This is consistent with a defect affecting methylation establishment or maintenance very early in development either in the maternal germ cells or pre-implantation embryo. Only one of the three cases had loss of methylation at other imprinted loci consistent with MLID. Patient B96 had complete LOM at the MEST locus on chromosome 7q32.2 but maintained a normal methylation at PLAGL1 (6q24), GRB10 (7p12.1) NESPAS (20q13)) and PEG3 (19q13). Interestingly, B96 had a brother who was stillborn, with an exomphalos and suspected BWS; however, this baby was born prior to the availability of molecular testing for BWS. Hence, for B96, there is a strong likelihood of an inherited predisposition. The mother of B97 was found to carry the R136C variant; however, she did not have features of BWS. Parental specimens from B96 and B66 were not available for testing. These patients also had less common variants in other folate pathway genes in varying combinations. All cases had at least two variant alleles corresponding to deleterious folate pathway polymorphisms in association with lowactivity variants of DNMT1. These variants have been 


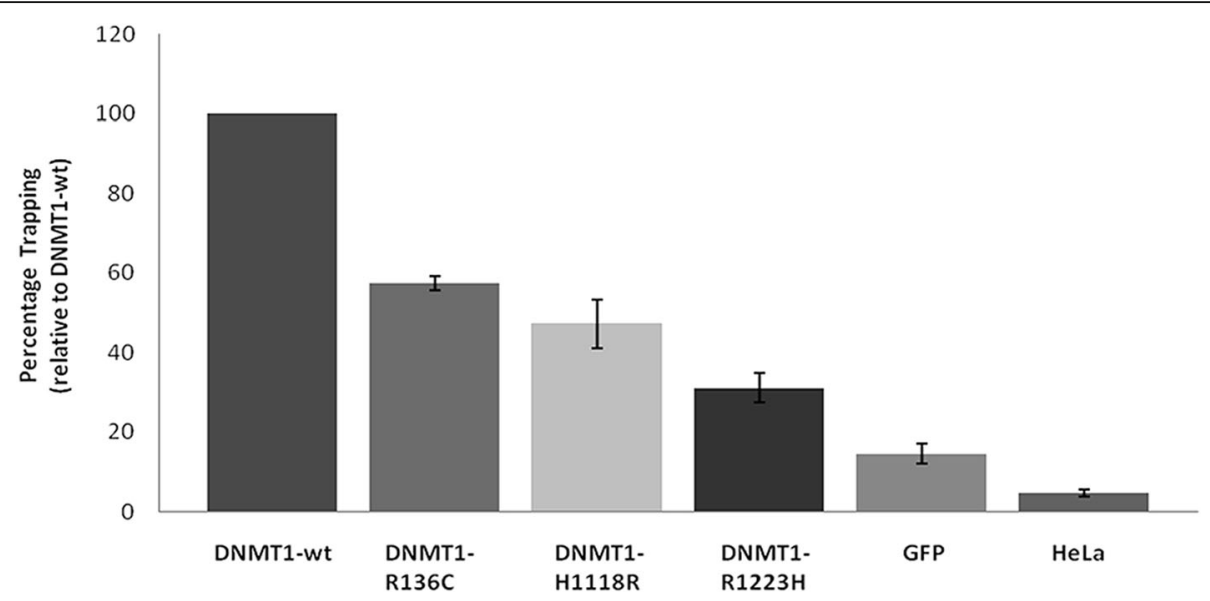

Fig. 4 DNMT1 methyltransferase trapping activity. The relative trapping ability of each DNMT1 variant is shown as a percentage relative to wild type DNMT1. Proteins from pEGFP-C1 transfected HeLa cells and non-transfected HeLa cells acted as controls. Technical replicates were performed in each assay. Four biological replicate experiments were performed for each sample and controls, except for DNMT1-R136C variant for which only three biological replicate experiments were performed. Error bars: mean $\pm \mathrm{SE}$

previously been shown to be associated with hypomethylation either dependent or independent of folate deficiency.

\section{Discussion}

In this paper, we have made observations that have not been previously reported. Firstly, patients with BWS and KCNQ1OT1 TSS-DMR LOM are more likely to have

Table 4 Clinical features of BWS KCNQ1OT1 TSS-DMR LOM cases with rare DNMT1 missense variants.

\begin{tabular}{llll}
\hline Clinical feature & B66 & B96 & B97 \\
& (p.Arg1223His) & (p.His1118Arg) & (p.Arg136Cys) \\
\hline Birth weight (kg) & 3.1 & 4.54 & 3.43 \\
$\begin{array}{l}\text { Neonatal } \\
\text { hypoglycaemia }\end{array}$ & $\mathrm{Y}$ & $\mathrm{N}$ & $\mathrm{N}$ \\
$\begin{array}{l}\text { Exomphalos/umbilical } \\
\text { hernia }\end{array}$ & $\mathrm{Y}$ & $\mathrm{Y}$ & $\mathrm{N}$ \\
Macroglossia & $\mathrm{Y}$ & $\mathrm{Y}$ & $\mathrm{Y}$ \\
Macrosomia & $\mathrm{N}$ & $\mathrm{Y}$ & $\mathrm{Y}$ \\
Ear creases & $\mathrm{Y}$ & $\mathrm{N}$ & $\mathrm{Y}$ \\
Malignancy & $\mathrm{N}$ & $\mathrm{N}$ & $\mathrm{N}$ \\
Facial naevus flammeus & $\mathrm{N}$ & $\mathrm{N}$ & $\mathrm{N}$ \\
Body asymmetry & $\mathrm{N}$ & $\mathrm{N}$ & $\mathrm{N}$ \\
Genitourinary & $\mathrm{N}$ & $\mathrm{N}$ & \\
abnormality & & & $\mathrm{N}$ \\
Hepatomegaly & $\mathrm{Y}$ & $\mathrm{N}$ & $\mathrm{N}$ \\
Nephromegaly & $\mathrm{N}$ & $\mathrm{N}$ & $\mathrm{N}$ \\
ART & $\mathrm{Y}$ & $\mathrm{Y}$ (sibling & $\mathrm{N}$ \\
Family history & $\mathrm{N}$ & $\mathrm{Fffected})$ & $\mathrm{M}$ \\
Sex & & $\mathrm{F}$ &
\end{tabular}

the low-activity MTHFR variant commonly known as c. 677C $>\mathrm{T}$ (rs1801133: $\mathrm{C}>\mathrm{T}$ ) although when applying a stringent statistical test for multiple testing, this association was not found to be statistically significant. BWS is a comparatively rare disorder, and examination of this relationship in larger cohorts will be required to consolidate it definitively. Secondly, we identified three rare missense variants of DNMT1 and DNMT1o and characterised their capacity for maintaining DNA methylation in vitro. All variants had impaired enzymatic activity compared to wild-type DNMT1.

A large body of evidence has previously implicated MTHFR rs1801133: C>T in hyper-homocysteinaemia and DNA hypomethylation, that is potentiated by low dietary folate and homozygosity for the T allele [17-20, 22, 34-37]. MTHFR rs1801133: C $>\mathrm{T}$ causes an amino acid substitution of highly conserved alanine to valine at position 222 (p.Ala222Val) resulting in reduced enzyme activity due to increased thermolability [16]. Furthermore, BWS has been reported previously in association with homocysteinuria occurring with $C B S$ enzyme deficiency [38]. Although we identified an association between the MTHFR rs1801133 $\mathrm{T}$ allele prevalence and BWS that was not statistically significant by a stringent statistical test, it remains to be determined whether a combination of low dietary folate and vitamin B6 and B12 deficiency, and this genotype may have a stronger association with BWS incidence. Future studies, including the prospective collection of dietary intake information, will require global collaborative efforts to examine these associations in large cohorts.

Our observations suggest that the identified low-activity DNMT1 variants may contribute to a subgroup of BWS cases with imprinting defects through the effects 
on the maintenance methylation of hemimethylated DNA during DNA replication prior to implantation. Given the observation of complete loss of methylation in all three cases with variant $D N M T 1$, we further propose that methylation maintenance failure at KCNQ1OT1 TSS-DMR occurs at a very early stage of embryogenesis in the cleavage embryo. Evidence from mouse models suggests a maternal effect on the maintenance of DNA methylation in the pre-implantation embryo. High levels of oocyte-derived maternal Dnmt1o are present in the cleavage embryo and protect imprinted loci from methylation loss at imprinted sites as well as in the intergenic regions. Mothers lacking Dnmt1o have abnormal imprinting in their offspring at the pre-implantation stage, including abnormal X-inactivation, in addition to placental hypomethylation [39]. Human DNMT1o is similarly expressed in mature oocytes and in early-stage embryonic development [32].

A direct role for DNMT1 in imprinting disorders as a result of maternal effect mutation is also suggested by the associations between the Uhrf1 protein and Dnmt1. Dnmt1 is recruited by Uhrf1 to replicating DNA [40], and intriguingly, a potentially deleterious UHRF mutation has been recently described as having a maternal effect in twins affected by MLID with loss of methylation [9]. Furthermore, another maternal effect protein, NLRP2, implicated in MLID and BWS, causes re-localization of Dnmt1 in oocytes and pre-implantation embryos [41]. Hence, there is accumulating evidence for the potential involvement of DNMT1 as a maternal effect protein associated with loss of methylation at imprinted loci.

Of the three cases with rare missense DNMT1 alleles, maternal inheritance of DNMT1 NM_001130823.1: c.406C > T, NP_001124295 p.Arg136Cys, could be demonstrated. Modes of inheritance could not be examined in the remaining two cases due to the lack of availability of parental DNA; however, case B96 had a sibling who was stillborn with exomphalos who was not tested for BWS, and the possibility of an inherited predisposition in this individual cannot be discounted. Case B66 with the variant DNMT1 NM_001130823.1: c.3668G>A，NP_001124295 p.Arg1223His, was a female conceived by intracytoplasmic sperm injection, and she also had a greater number of the clinical features of BWS when compared with the other two cases (five versus three in the other DNMT1 variant cases). It is not known whether she had inherited the DNMT1 variant from either of her parents; however, maternal inheritance would be consistent with recent observations in the mouse showing that oocytes deficient in Dnmt1o are more susceptible to imprinting defects following ART [42].

There was no reported indication of parental or familial BWS in any case. However, this might not be unexpected in a scenario where a DNMT1 mutation has a maternal effect in the pre-implantation embryo. Mothers may be mutation carriers themselves but unaffected if they had inherited a deleterious DNMT1 SNV from their fathers or had acquired one de novo. In such circumstances, only offspring arising from an oocyte expressing abnormal DNMT1 protein would be affected.

Previous studies on mouse Dnmt1s have identified regions required for maintenance of imprinting that are localised to the region spanning amino acids 191-394; however, none of the variants in this study are located within this domain [27]. The variant DNMT1 NM_001130823.1: c.406C>T, NP_001124295 p.Arg136Cys, lies within an interaction site with DNMT3A suggesting the possibility of an effect on imprint establishment, given the evidence for coordination between DNMT1, DNMT3a and DNMT3b in both establishing and maintaining methylation [43, 44]. Recent studies have revealed insight into the structure of human DNMT1 protein, and conserved domains are described for DNMT1 NP_001124295.1 in the Conserved Domain Database hosted by NCBI [45-47]. None of the identified variants was located directly within the enzymatic active site at Cysteine 1242 in Ref Seq NP_001124295. Variant DNMT1: NP_001124295 p.His1118Arg is immediately adjacent to the second bromo-adjacent homology (BAH2) domain, and variant DNMT1: NP_001124295 p.Arg1223His lies within the catalytic domain. Histidine at 1118 is distant (> $45 \AA$ away) from the DNA binding, SAM binding and catalytic cysteine within the catalytic domain. In the DNMT1 structures, this residue is in a short helix where it is solvent exposed and has few intra-molecular interactions (structure 3PTA in [47] and structure 4WXX in [46]). Residue Arg1223 is in the catalytic domain and distant from the DNA, SAM and Cys1242 sites (21 $\AA$, < $15 \AA,<28 \AA$, respectively). This residue is leucine in mouse Dnmt1 (structure PDB ID 4DA4 [48], and both residues occupy similar structural space at the apex of a loop. In the human DNMT1 structures (PDB IDS 4WXX, 3PTA), the arginine adopts two radically side chain conformations. In both configurations, the arginine side chain does not engage in intra-molecular polar contacts and the residue is solvent exposed. The loop in which the DNMT1: NP_001124295 p.Arg1223His variant is found is added during the evolution of cytosine C5 methyltransferases. The loop is absent in the methyltransferase from Haemophilus parahaemolyticus (HhaI) [49] that has high structural similarity to the mouse and human DNMT1 catalytic domain, suggesting it is an acquired adaptation and not evolutionarily required for activity. Previous work found that DNMT1 mutations that cause hereditary sensory neuropathy were due to protein misfolding [50]. One residue was in a hydrophobic core region while the other was in a linker region between secondary structural 
elements. Both mutations were found to affect the folding and stability of DNMT1 protein. In contrast, the variants reported here are in surface-exposed regions and are unlikely to be involved in the intra-molecular interactions. Therefore, they are not proposed to affect folding or stability. However, despite sharing $80 \%$ sequence identity, recent subtle differences in function between the mouse and human structures of DNMT1 protein have been recently recognised [46]. Therefore, any definitive structural effects of the identified variants are currently unclear. It may be possible that mutations exert their effects by altering conformational flexibility that is not apparent in the crystal structure. It is interesting to note however that the effect of the DNMT1: NP_001124295 p.Arg1223His variant on the activity was the strongest in the trapping assay and comparable to the effects described for DNMT1 variants reported in the previous study examining hereditary neuropathies [50].

In a setting of maternal dietary folate deficiency or impaired embryonic folate metabolism, the observed decrease in DNMT1 enzymatic activity could be further exaggerated by reduced availability of the substrate $S$-adenosyl methionine (SAM) or increases in inhibitory $S$-adenosylhomocyteine (SAH). Interestingly, all cases with variant DNMT1 had at least two variants predicted to adversely affect folate metabolism via the effects directly on MTHFR and methylation of tetrahydrofolate or via the effects on the conversion of homocysteine to methionine via methionine synthase reductase (MTRR) and 5-methyltetrahydrofolate-homocysteine $S$-methyltransferase (MTR) using vitamin $\mathrm{B} 12$ as a cofactor.

Due to their rarity in the general population, presence in a subgroup of BWS and MLID cases, and functional characterization supporting reduced methyltransferase activity, these DNMT1 variants are worthy of reporting. Ultimately, mouse models examining the effect of variant DNMT1 in the context of imprinting disruption at specific loci including KCNQ1OT1 TSS-DMR will be required for proof of association; however, larger cohort studies on families with imprinting disorders are also likely to be fruitful.

\section{Conclusions}

In conclusion, the observations from this study suggest that novel genetic factors affecting DNA methylation may cause imprinting disruption in a subgroup of BWS cases. This study paves the way for larger prospective studies in BWS and other human imprinting disorders to examine the relationship between genotypes linked to DNA methylation in concert with environmental factors, to fully elucidate the causes of abnormal genomic imprinting.

\section{Methods}

\section{Participant recruitment}

The laboratory in which this work was conducted is the primary referral laboratory for the diagnosis of BWS in Australasia. After diagnostic testing for BWS using methylation-sensitive MLPA (MS-MLPA) to interrogate imprinting defects in 11p15.5, patients with evidence of sporadic loss of methylation at KCNQ1OT1 TSS-DMR were invited to participate in this research project. Parents were asked to complete a clinical questionnaire from which data on clinical features and fertility history were collected. The project and consent forms were approved by the Human Research Ethics Committee of the Royal Children's Hospital in Melbourne (HREC 21121M), where the work was conducted. The participant recruitment extended over a period of 5 years.

Cord blood samples used as controls were obtained from the BMDI Cord Blood Bank at the Royal Children's Hospital, Melbourne, Australia. These samples were deemed unsuitable for transplantation and approved for use in this project by the local institutional ethics committee.

\section{Molecular diagnosis of Beckwith-Wiedemann syndrome}

Patients referred to the laboratory were assessed as having BWS with isolated loss of methylation at 11p15.5 KCNQ1OT1 TSS-DMR using the Salsa ME030-B1 BWS/ RSS MS MLPA kit (MRC Holland). Patients with either partial or complete loss of methylation at KCNQ1OT1 TSS-DMR were included in the study. H19 methylation abnormalities and patUPD11p15 were not present in any cases included. DNA was extracted from EDTA blood using the Puregene kit (Qiagen Hilden Germany) and stored at $-20{ }^{\circ} \mathrm{C}$ prior to use.

\section{PCR and high-resolution melting}

PCR was performed in a 20- $\mu$ l total volume on all samples using HotStar Taq DNA Polymerase (Qiagen). Typical cycling conditions were $95{ }^{\circ} \mathrm{C}$ for $15 \mathrm{~min}$ followed by 40 cycles of $95^{\circ} \mathrm{C}$ for $30 \mathrm{~s}$, annealing temperature for $30 \mathrm{~s}$, extension at $72{ }^{\circ} \mathrm{C}$ for $45 \mathrm{~s}$ followed by a final extension at $72{ }^{\circ} \mathrm{C}$ for $5 \mathrm{~min}$. HRM reactions were performed in a total volume of $20 \mu \mathrm{L}$ and comprised $2 \times$ HRM Sensimix (Bioline) $(10 \mu \mathrm{L}), 0.50 \mu \mathrm{L}$ of forward and reverse primers at $20 \mu \mathrm{M}, 1.0 \mu \mathrm{L}$ of DNA at $10 \mathrm{ng} / \mu \mathrm{L}$. Amplification reactions were $95{ }^{\circ} \mathrm{C}$ for $10 \mathrm{~min}$, followed by 40 cycles of $95{ }^{\circ} \mathrm{C}$ for $15 \mathrm{~s}$, annealing temperature for $10 \mathrm{~s}, 72{ }^{\circ} \mathrm{C}$ for $10 \mathrm{~s}$ followed by $72{ }^{\circ} \mathrm{C}$ for $5 \mathrm{~min}$. Primers used in PCR, HRM and sequencing are described in the Additional file 1: Tables S2a-e, S3a-e and S4a-c.

\section{Sanger sequencing}

PCR products were treated with ExoSAP-IT (USB, Affymetrix) and sequenced with Big Dye Terminator v3.1 (BDT) mix (Applied Biosystems) according to the 
manufacturer's instructions. Sequences were analysed with Mutation Surveyor v 4.0 (SoftGenetics, USA).

\section{Variant classification}

Variants were examined using Polyphen (genetics.bwh.harvard.edu/pph2/), SIFT (sift.bii.a-star.edu.sg) Variant Effect Prediction tool (https://www.ensembl.org/vep) [51], Mutation Taster (www.mutationtaster.org/) and the University of Maryland Genetic Variant Interpretation tool.

SNVs are reported relative to their cDNA reference sequences where the nucleotide numbering uses +1 as the A of the ATG translation initiation codon. Reference sequences used are as follows: MTHFR NM_005957.4, MTRR NM_002454.2, MAT1A NM_00429.2, MTR NM_000254.2, CBS NM_001178009.1 and DNMT1 NM_001130823.1. The DNMT1 genomic reference sequence used for intronic variants was NC_000019.10.

\section{Analysis of methylation at other centres of genomic imprinting}

The PLAGL (6q24), GRB10 (7p12.1), NESPAS (20q13) and PEG3 (19q13) loci were evaluated for methylation by pyrosequencing. Methylation at the MEST locus was evaluated by MS-MLPA.

Genomic DNA samples from 55 BWS cases with KCNQ1OT1 TSS-DMR LOM and from 13 controls were bisulphite modified using the MethylEasy DNA bisulphite modification kit (Cat No: ME-001, Human Genetic Signatures). Pyrosequencing PCR and sequencing primers were based on those described in Mackay et al. [52]. Primers for PCR are listed in Additional file 1: Table S5a, and primers used for sequencing are listed in Additional file 1: Table S5b. PCR was performed in a $40-\mu \mathrm{L}$ total volume of $1 \times$ HotStar Master mix with $0.2 \mu \mathrm{L}$ HotStar Taq DNA Polymerase (Cat. No: 203203, Qiagen), $0.2 \mu \mathrm{L}$ of $20 \mu \mathrm{M}$ forward and reverse primers, $5 \times \mathrm{Q}$ solution (Qiagen) and $0.2 \mathrm{mM}$ dNTPs. PCR cycling was at $95{ }^{\circ} \mathrm{C}$ for $15 \mathrm{~min}$, followed by 45 cycles at $95{ }^{\circ} \mathrm{C}$ for $30 \mathrm{~s}$, annealing temperature for $30 \mathrm{~s}$ and extension for $45 \mathrm{~s}$ at $72{ }^{\circ} \mathrm{C}$. Pyrosequencing was performed on a PyroMark Q24 (Cat. \#9001514, Qiagen) using PyroMark Q24 Gold (Cat. \#970802, Qiagen) according to the manufacturer's protocol. The results were analysed using PyroMark Q24 software to determine the methylation status. Thirteen control samples were used to establish the mean methylation values across the CpG sites examined. A normal range was considered to be the mean value \pm two standard deviations from the mean. Patients were scored as abnormal if methylation was outside the established normal range. The MEST locus at 7q32.1 was examined using the SALSA MLPA kit ME032-A1 UPD7/UPD14 (MRC Holland) according to the manufacturer's instructions. Two specimens previously reported with genome-wide mosaic uniparental isodisomy
[53] were used as positive controls for loss of methylation. Loss of methylation at MEST was scored as positive when methylation was $<0.35$.

\section{Generation of DNMT1 plasmids}

The mammalian expression vector containing the long isoform of wild-type human DNMT1 with N-terminal GFP tag in pEGFP-C1 plasmid (Clontech) was obtained from Prof. Heinrich Leonhardt (Ludwig-Maximilians-University Biocentre, Munich). The pEGFP-C1-DNMT1 construct was transfected into competent DH5-alpha cells, and construct fidelity was assessed by sequencing plasmid DNA using primers designed to DNMT1 exons as described in the supplementary information (cDNMT1 sequencing primers).

Bacterial cultures containing pEGFP-C1-DNMT1 were grown in $2 \mathrm{YT}$ and kanamycin and plasmid DNA extracted with either QIAprep Spin MiniPrep kit (Cat. \# 27104, Qiagen) or Plasmid Maxi kit (Cat. \#12162, Qiagen) appropriate to the scale of the culture and according to the manufacturer's instructions.

\section{Site-directed mutagenesis}

DNMT1 coding variations were inserted into the wildtype DNMT1 sequence in pEGFP-C1. Mutagenesis was performed with QuikChange II Site-Directed Mutagenesis kit (Cat. \#200523, Agilent Technologies) according to the manufacturer's instructions. Mutagenic primer pairs were designed for each identified DNMT1 sequence variant using a web-based primer design tool (www.agilent.com/genomics/qcpd) provided by Agilent Technologies. The primers are listed following. $\mathrm{Mu}-$ tated sites are underlined:

DNMT1406C $>$ T, F: CCAAACCCCTTTCCAAACC TTGCACGCCCAGG, R: CCTGGGCGTGCAAGGT TT̄GGAAAGGGGTTTGG; DNMT1 3353A $>$ G, F: GATCCTCCCAACCGTGCCCGTA GCCCT, R: AGGG CTACGGGCACGGTTGGGAGGATC; and DNMT1 3668G >A F: CĀCCA ACTCCCACGGCCAGCGGC, R: GCCGCTGGCCGTGGGAGTTGGTG.

Following selection in kanamycin $(50 \mu \mathrm{g} / \mathrm{mL})$, white colonies derived from pEGFP-C1-DNMT1 mutants were selected and sequenced to confirm the presence of the mutation. Sequence traces from mutants are shown in Additional file 2: Figure S2.

\section{Transfection of DNMT1 into Hela cells}

Wild-type DNMT1 and DNMT1 mutant plasmids were transfected into HeLa cells using FugeneHD (Promega) at a volumetric ratio of 3:1. Transfection efficiency was analysed by flow cytometry (BD LSR II, BD Biosciences) after $48 \mathrm{~h}$. HeLa cells were transfected at a density of $1 \times 10^{5}$ cells per well in a 12-well plate in $1 \mathrm{ml}$ of DMEM containing 10\% FCS (SAFC BioSciences) and 
incubated at $37{ }^{\circ} \mathrm{C}$ in $5 \% \mathrm{CO}_{2}$. Nuclear GFP expression was visualised by confocal microscopy on a Leica TCS SP2. Transfection efficiencies of $60-70 \%$ were achieved.

\section{Purification of GFP-tagged DNMT1 proteins}

The GFP-Trap_A kit (Chromotek) was used to purify GFP-tagged DNMT1 proteins from HeLa cells according to the manufacturer's instructions.

\section{Protein analysis and Western blotting}

Total protein estimation using the bichoninic acid (BCA) assay (Sigma-Aldrich) was performed on $20 \mu \mathrm{L}$ cell lysate according to the manufacturer's instructions. Western blotting with fluorescence visualization was performed as described in [54].

Purified GFP-tagged DNMT1 protein bound to beads was quantified using a DNMT1 ELISA kit (Epigentek Cat \#P-3011). Standards were prepared from 7.5, 10, 12.5 and 15 ng of purified DNMT1 (supplied in the kit), and absorbance was read at 450 and $620 \mathrm{~nm}$ on a Multiskan EX microplate reader (Thermo Electron).

\section{Measurement of DNA methyltransferase activity}

The DNA methyltransferase activity of the generated wild-type and mutant DNMT1 proteins was measured by an irreversible covalent interaction with a hemimethylated trapping substrate containing 5-aza$2{ }^{\prime}$-deoxycytidine (5-azadC) as described in [55] and outlined below and in Additional file 2: Figure S4. This reaction is designed to irreversibly "trap" active DNMT1 in an inactive conformation by binding to the mechanism-based inhibitor 5-azadC. Capture and detection of this reaction intermediate serve as a measure of DNMT1 enzyme activity. Oligonucleotides used for the preparation of the DNA trapping substrate were synthesised by Integrated DNA Technologies. The forward oligo, MG-Upper contains a methylated cytosine $(\underline{M})$ and the reverse 3' endpaired Fill-in-oligo is labelled with a MAX-NHS ester fluorescent dye at its $5^{\prime}$ end. The Fill-in-oligo is complementary to the $3^{\prime}$ end of the MG-Upper oligonucleotide. Oligo sequences were as follows: MGUpper 5' CTCAACAACTAACTACCATCMGGACCAGAA GAGTCATCATGG $3^{\prime}$ and Fill-in 5'MAXN-CCAT GATGACTCTTCTGGTC 3 '.

Double-stranded DNA generated by oligo extension was prepared by denaturing $1 \mu \mathrm{L}$ of each oligo at $100 \mu \mathrm{M}$ in NEB2 buffer at $95^{\circ} \mathrm{C}$ for $2 \mathrm{~min}$ followed by a slow cooling to $37^{\circ} \mathrm{C}$ in a total final reaction volume of $15.2 \mu \mathrm{L}$. Hemimethylated DNA substrate was synthesised by extension of the fill-in-oligo with the addition of $1 \mu \mathrm{L}$ DNA Polymerase I (Large Klenow) fragment (Cat \#M2201, Promega), $1 \mathrm{mM}$ each of dTTP, dATP and dGTP (Cat \#BIO-39025, Bioline) and $50 \mu \mathrm{M}$ 5-aza-dCTP (Cat
\#NU-1118S, Jena Bioscience) in acetylated BSA at $20 \mathrm{ng} /$ $\mu \mathrm{L}$ (Cat \#R3961, Promega) in a final reaction volume of $20 \mu \mathrm{L}$. The mix was incubated at room temperature for $10 \mathrm{~min}$ followed by inactivation at $75^{\circ} \mathrm{C}$ for $10 \mathrm{~min}$. This preparation of trapping substrate was used immediately in the in vitro DNMT1 trapping assay described below.

Fifteen nanograms of each purified pull-down GFPtagged DNMT1 protein (bead-bound) derived from each DNMT1 protein variant was resuspended in buffer $(100 \mathrm{mM} \mathrm{KCl}, 10 \mathrm{mM}$ Tris- $\mathrm{HCl}, \mathrm{pH}$ 7.6, $1 \mathrm{mM}$ EDTA, $1 \mathrm{mM}$ DTT) supplemented with $100 \mu \mathrm{M} S$-adenosyl-L-methionine (SAM) (New England Biolabs, Cat \#B9003S), $4 \mu \mathrm{L}$ end-labelled DNA trapping substrate (prepared as described above) and $160 \mathrm{ng} / \mu \mathrm{L}$ BSA in a total reaction volume of $200 \mu \mathrm{L}$. For determination of DNA methyltransferase activity, trapping was performed at $37{ }^{\circ} \mathrm{C}$ for 90 min with constant mixing. To remove unbound substrate, beads were washed twice with $1 \mathrm{~mL}$ of assay buffer, then resuspended in $100 \mu \mathrm{L}$ of assay buffer and transferred to a 96-well microplate. Bound-labelled DNA trapping substrate associated with each variant and wild-type DNMT1 protein was measured by fluorescence emission on a FLUOstar Optima microplate reader (BMG Labtech). Technical duplicates were tested in each assay, and assays were performed in quadruplicate for each variant (except for DNMT1 Arg136Cys for which triplicate assays were performed) and the mean fluorescence for each DNMT1 variant was normalised to the wild-type DNMT1 fluorescence value, set to $100 \%$. A schematic representation of the preparation of the DNA suicide substrate and the trapping assay is shown in Additional file 2: Figure S4.

\section{Statistical analysis}

Calculations of chi-squared and significance values were calculated using online analysis tools including GraphPad. Allele association was calculated using a $2 \times$ contingency table with one degree of freedom [56]. Probability values of $p<0.05$ were considered to be statistically significant. Pearson values for chi-squared and probability were calculated. Bonferroni correction was also applied for the analysis of folate pathway SNVs to adjust for multiple testing.

\section{Additional files}

Additional file 1: Table S1. Methylation at non-11p15 imprinting centres in BWS cases with loss of methylation at KCNQ1OT1 TSS-DMR. Only samples with identified methylation changes are listed. Tables S2. a-e Primers used for HRM of MTHFR, MTR, MTRR, MAT1A, CBS. Table S3. a-e Primers used for sequencing MTHFR, MTR, MTRR, MAT1A, CBS. Table S4. a-d. DNMT1 primers. Table S5 Pyrosequencing primers. (DOCX $226 \mathrm{~kb}$ )

Additional file 2: Figure S1. DNMT1 sequence variants identified in BWS patients. Figure S2. Sequence traces of DNMT1 variants generated by site-directed mutagenesis. Figure S3. Expression of GFP-tagged 
DNMT1 proteins in HeLa cells. Figure S4. Schematic of the trapping assay adapted from Frauer and Leonhardt (2009). (PPTX $1525 \mathrm{~kb}$ )

\section{Abbreviations}

BWS: Beckwith-Wiedemann syndrome; CBS: Cystathionine beta-synthase; DNMT1: DNA methyltransferase 1; MAT1A: Methionine adenosyltransferase; MLID: Multi-locus imprinting disruption; MTHFR: Methylenetetrahydrofolate reductase; MTR: 5-Methyltetrahydrofolate-homocysteine S-methyltransferase MTRR: Methionine synthase reductase; SAH: S-adenosyl-homocysteine; SAM: S-adenosyl-methionine; SNV: Single nucleotide variant

\section{Funding}

This study was funded by the David Danks Post Graduate Scholarship (University of Melbourne) and the Children's Cancer Foundation (Murdoch Children's Research Institute). The funding bodies had no role in the design of the study, collection, analysis, interpretation of data, or in writing the manuscript.

\section{Availability of data and materials}

All relevant data generated or analysed in this study are included in this published article and its Additional files.

\section{Authors' contributions}

EA and VD designed the study. VD, WH, PS and AM performed the experiments and genetic analyses. EA, VD, DA and JM analysed the data. $D H$ and $A B$ performed the DNMT1 protein modelling and edited the manuscript. EA wrote the manuscript. DA, JP, AC, MW, RS, GMCG, ME, EK, FC, KJ, JT, IH, $E T, C B, E H, M-L F, A T, S W, B K, A M a, F M, G B, C K-B, M F$ and TD-B consented participants, facilitated the provision of clinical information and critically reviewed and edited the manuscript. DA and EK provided input to the statistical analysis. All authors read and approved the final manuscript.

\section{Ethics approval and consent to participate}

The project and consent forms were approved by the Human Research Ethics Committee of the Royal Children's Hospital in Melbourne (HREC 21121M). All participants or their guardians gave written consent for participation.

\section{Consent for publication}

The participant information statement and consent form includes a statement about publication.

Consent for participation includes consent for publication.

\section{Competing interests}

The authors declare that they have no competing interests.

\section{Publisher's Note}

Springer Nature remains neutral with regard to jurisdictional claims in published maps and institutional affiliations.

\footnotetext{
Author details

'Department of Paediatrics, University of Melbourne, Parkville 3052, Australia. ${ }^{2}$ Pathology, Monash Health, Clayton 3168, Australia. ${ }^{3}$ School of Medicine, Deakin University, Geelong 3216, Australia. ${ }^{4}$ Victorian Comprehensive Cancer Centre, Parkville 3052, Australia. ${ }^{5}$ Department of Biochemistry and Molecular Biology, Monash University, Clayton 3800, Australia. ${ }^{6}$ Murdoch Children's Research Institute, Parkville 3052, Australia. ${ }^{7}$ Department of Anatomy and Developmental Biology, Monash University, Clayton 3800, Australia. ${ }^{8}$ Department of Medical Genomics, Royal Prince Alfred Hospital, Camperdown 2050, Australia. ${ }^{9} \mathrm{Clinical}$ Genetics, Liverpool Hospital, Liverpool 2170, Australia. ${ }^{10} \mathrm{Clinical}$ Genetics, Children's Hospital at Westmead, Westmead 2145, Australia. ${ }^{11}$ Centre for Clinical Genetics, Sydney Children's Hospital, Randwick 2031, Australia. ${ }^{12}$ School of Medicine, University of Western Sydney, Penrith 2751, Australia. ${ }^{13}$ School of Medicine, University of Sydney, Camperdown 2006, Australia. ${ }^{14}$ Auckland District Health Board, Auckland 1023, New Zealand. ${ }^{15}$ South Australian (SA) Clinical Genetics Service, SA Pathology, Women's and Children's Hospital, Adelaide 5000, Australia. ${ }^{16}$ School of Medicine, University of Adelaide, Adelaide 5000, Australia. ${ }^{17}$ Department of Clinical Genetics, Royal North Shore Hospital, St Leonards 2065, Australia. ${ }^{18}$ School of Women's and Children's Health, University of NSW, Kensington 2052, Australia. ${ }^{19}$ Hunter Genetics, Hunter New England Local Health District, New Lambton 2305, Australia. ${ }^{20}$ Genetics
}

Services of Western Australia, Crawley 6009, Australia. ${ }^{21}$ University of Newcastle GrowUpWell Priority Research Centre, Callaghan 2308, Australia.

${ }^{22}$ Hudson Institute of Medical Research, Clayton 3168, Australia.

${ }^{23}$ Department of Translational Medicine, Monash University, Clayton 3168, Australia.

Received: 19 April 2018 Accepted: 17 August 2018

Published online: 30 August 2018

\section{References}

1. Weksberg R, Nishikawa J, Caluseriu O, Fei YL, Shuman C, Wei C, Steele L, Cameron J, Smith A, Ambus I, et al. Tumor development in the Beckwith-Wiedemann syndrome is associated with a variety of constitutional molecular 11p15 alterations including imprinting defects of KCNQ1OT1. Hum Mol Genet. 2001;10:2989-3000.

2. Weksberg R, Shuman C, Beckwith JB. Beckwith-Wiedemann syndrome. Eur J Hum Genet. 2010;18:8-14.

3. Mussa A, Molinatto C, Baldassarre G, Riberi E, Russo S, Larizza L, Riccio A, Ferrero GB. Cancer risk in Beckwith-Wiedemann syndrome: a systematic review and meta-analysis outlining a novel (epi)genotype specific histotype targeted screening protocol. J Pediatr. 2016;176:142-9. e141

4. Maas SM, Vansenne F, Kadouch DJ, Ibrahim A, Bliek J, Hopman S, Mannens MM, Merks JH, Maher ER, Hennekam RC. Phenotype, cancer risk, and surveillance in Beckwith-Wiedemann syndrome depending on molecular genetic subgroups. Am J Med Genet A. 2016;170:2248-60.

5. Diaz-Meyer N, Day CD, Khatod K, Maher ER, Cooper W, Reik W, Junien C, Graham G, Algar E, Der Kaloustian VM, Higgins MJ. Silencing of CDKN1C (p57KIP2) is associated with hypomethylation at KvDMR1 in Beckwith-Wiedemann syndrome. J Med Genet. 2003;40:797-801.

6. Algar E, Dagar V, Sebaj M, Pachter N. An 11p15 imprinting centre region 2 deletion in a family with Beckwith Wiedemann syndrome provides insights into imprinting control at CDKN1C. PLoS One. 2011;6:e29034.

7. Meyer E, Lim D, Pasha S, Tee LJ, Rahman F, Yates JR, Woods CG, Reik W, Maher ER. Germline mutation in NLRP2 (NALP2) in a familial imprinting disorder (Beckwith-Wiedemann syndrome). PLoS Genet. 2009;5:e1000423.

8. Docherty LE, Rezwan Fl, Poole RL, Turner CL, Kivuva E, Maher ER, Smithson SF, Hamilton-Shield JP, Patalan M, Gizewska M, et al. Mutations in NLRP5 are associated with reproductive wastage and multilocus imprinting disorders in humans. Nat Commun. 2015;6:8086.

9. Begemann M, Rezwan Fl, Beygo J, Docherty LE, Kolarova J, Schroeder C, Buiting K, Chokkalingam K, Degenhardt F, Wakeling EL, et al. Maternal variants in NLRP and other maternal effect proteins are associated with multilocus imprinting disturbance in offspring. J Med Genet. 2018;55(7):497-504.

10. Sato A, Otsu E, Negishi H, Utsunomiya T, Arima T. Aberrant DNA methylation of imprinted loci in superovulated oocytes. Hum Reprod. 2007;22:26-35.

11. DeBaun MR, Niemitz EL, Feinberg AP. Association of in vitro fertilization with Beckwith-Wiedemann syndrome and epigenetic alterations of LIT1 and H19. Am J Hum Genet. 2003;72:156-60.

12. Halliday J, Oke K, Breheny S, Algar E, JA D. Beckwith-Wiedemann syndrome and IVF: a case-control study. Am J Hum Genet. 2004;75:526-8.

13. Manipalviratn S, DeCherney A, Segars J. Imprinting disorders and assisted reproductive technology. Fertil Steril. 2009;91:305-15.

14. Maher ER, Afnan M, Barratt CL. Epigenetic risks related to assisted reproductive technologies: epigenetics, imprinting, ART and icebergs? Hum Reprod. 2003;18:2508-11.

15. Maher ER, Brueton LA, Bowdin SC, Luharia A, Cooper W, Cole TR, Macdonald F, Sampson JR, Barratt CL, Reik W, Hawkins MM. BeckwithWiedemann syndrome and assisted reproduction technology (ART). J Med Genet. 2003;40:62-4.

16. Frosst P, Blom HJ, Milos R, Goyette P, Sheppard CA, Matthews RG, Boers GJ, den Heijer $M$, Kluijtmans $L A$, van den Heuvel $L P$, et al. A candidate genetic risk factor for vascular disease: a common mutation in methylenetetrahydrofolate reductase. Nat Genet. 1995;10:111-3.

17. Rozen R. Molecular genetics of methylenetetrahydrofolate reductase deficiency. J Inherit Metab Dis. 1996;19:589-94.

18. Eskes TK. Open or closed? A world of difference: a history of homocysteine research. Nutr Rev. 1998;56:236-44.

19. Botto LD, Yang Q. 5,10-methylenetetrahydrofolate reductase gene variants and congenital anomalies: a HuGE review. Am J Epidemiol. 2000;151:862-77.

20. Fodinger M, Horl WH, Sunder-Plassmann G. Molecular biology of 5,10methylenetetrahydrofolate reductase. J Nephrol. 2000;13:20-33. 
21. van der Put NM, Gabreels F, Stevens EM, Smeitink JA, Trijbels FJ, Eskes TK, van den Heuvel LP, Blom HJ. A second common mutation in the methylenetetrahydrofolate reductase gene: an additional risk factor for neural-tube defects? Am J Hum Genet. 1998;62:1044-51.

22. Castro R, Rivera I, Ravasco P, Camilo ME, Jakobs C, Blom HJ, de Almeida IT. 5,10-Methylenetetrahydrofolate reductase (MTHFR) 677C-->T and 1298A-->C mutations are associated with DNA hypomethylation. J Med Genet. 2004;41:454-8.

23. Leclerc D, Campeau E, Goyette P, Adjalla CE, Christensen B, Ross M, Eydoux $P$, Rosenblatt DS, Rozen R, Gravel RA. Human methionine synthase: CDNA cloning and identification of mutations in patients of the cblG complementation group of folate/cobalamin disorders. Hum Mol Genet. 1996:5:1867-74.

24. Watkins D, Rosenblatt DS. Genetic heterogeneity among patients with methylcobalamin deficiency. Definition of two complementation groups, cblE and cblG. J Clin Invest. 1988;81:1690-4.

25. van der Put NM, van der Molen EF, Kluijtmans LA, Heil SG, Trijbels JM, Eskes TK, Van Oppenraaij-Emmerzaal D, Banerjee R, Blom HJ. Sequence analysis of the coding region of human methionine synthase: relevance to hyperhomocysteinaemia in neural-tube defects and vascular disease. QJM. 1997;90:511-7.

26. Vaughn JD, Bailey LB, Shelnutt KP, Dunwoody KM, Maneval DR, Davis SR, Quinlivan EP, Gregory JF 3rd, Theriaque DW, Kauwell GP. Methionine synthase reductase $66 \mathrm{~A}->\mathrm{G}$ polymorphism is associated with increased plasma homocysteine concentration when combined with the homozygous methylenetetrahydrofolate reductase $677 \mathrm{C}->$ T variant. J Nutr. 2004;134:2985-90.

27. Borowczyk E, Mohan KN, D'Aiuto L, Cirio MC, Chaillet JR. Identification of a region of the DNMT1 methyltransferase that regulates the maintenance of genomic imprints. Proc Natl Acad Sci U S A. 2009;106:20806-11.

28. Ding F, Chaillet JR. In vivo stabilization of the Dnmt1 (cytosine-5)methyltransferase protein. Proc Natl Acad Sci U S A. 2002;99:14861-6.

29. Kurihara Y, Kawamura Y, Uchijima Y, Amamo T, Kobayashi H, Asano T, Kurihara $\mathrm{H}$. Maintenance of genomic methylation patterns during preimplantation development requires the somatic form of DNA methyltransferase 1. Dev Biol. 2008;313:335-46.

30. Hirasawa R, Chiba H, Kaneda M, Tajima S, Li E, Jaenisch R, Sasaki H. Maternal and zygotic Dnmt1 are necessary and sufficient for the maintenance of DNA methylation imprints during preimplantation development. Genes Dev. 2008;22:1607-16.

31. Gaudet F, Talbot D, Leonhardt $H$, Jaenisch R. A short DNA methyltransferase isoform restores methylation in vivo. J Biol Chem. 1998:273:32725-9.

32. Hayward BE, De Vos M, Judson H, Hodge D, Huntriss J, Picton HM, Sheridan E, Bonthron DT. Lack of involvement of known DNA methyltransferases in familial hydatidiform mole implies the involvement of other factors in establishment of imprinting in the human female germline. BMC Genet. 2003;4:2.

33. Mussa A, Russo S, De Crescenzo A, Chiesa N, Molinatto C, Selicorni A, Richiardi L, Larizza L, Silengo MC, Riccio A, Ferrero GB. Prevalence of Beckwith-Wiedemann syndrome in north west of Italy. Am J Med Genet A. 2013;161a:2481-6

34. Haggarty $P$, McCallum H, McBain H, Andrews K, Duthie S, McNeill G, Templeton A, Haites N, Campbell D, Bhattacharya S. Effect of B vitamins and genetics on success of in-vitro fertilisation: prospective cohort study. Lancet. 2006;367:1513-9.

35. Friso S, Choi SW, Girelli D, Mason JB, Dolnikowski GG, Bagley PJ, Olivieri O, Jacques PF, Rosenberg $\mathrm{H}$, Corrocher R, Selhub J. A common mutation in the 5,10-methylenetetrahydrofolate reductase gene affects genomic DNA methylation through an interaction with folate status. Proc Natl Acad Sci U S A. 2002;99:5606-11.

36. Stern LL, Mason JB, Selhub J, Choi SW. Genomic DNA hypomethylation, a characteristic of most cancers, is present in peripheral leukocytes of individuals who are homozygous for the C677T polymorphism in the methylenetetrahydrofolate reductase gene. Cancer Epidemiol Biomark Prev. 2000;9:849-53.

37. Yamada K, Chen Z, Rozen R, Matthews RG. Effects of common polymorphisms on the properties of recombinant human methylenetetrahydrofolate reductase. Proc Natl Acad Sci U S A. 2001;98:14853-8.

38. Levy HL, Vargas JE, Waisbren SE, Kurczynski TW, Roeder ER, Schwartz RS, Rosengren S, Prasad C, Greenberg CR, Gilfix BM, et al. Reproductive fitness in maternal homocystinuria due to cystathionine beta-synthase deficiency. J Inherit Metab Dis. 2002;25:299-314.

39. McGraw S, Oakes CC, Martel J, Cirio MC, de Zeeuw P, Mak W, Plass C, Bartolomei MS, Chaillet JR, Trasler JM. Loss of DNMT1o disrupts imprinted X chromosome inactivation and accentuates placental defects in females. PLoS Genet. 2013;9:e1003873.

40. Bostick M, Kim JK, Esteve PO, Clark A, Pradhan S, Jacobsen SE. UHRF1 plays a role in maintaining DNA methylation in mammalian cells. Science. 2007; 317:1760-4.

41. Mahadevan S, Sathappan V, Utama B, Lorenzo I, Kaskar K, Van den Veyver IB. Maternally expressed NLRP2 links the subcortical maternal complex (SCMC) to fertility, embryogenesis and epigenetic reprogramming. Sci Rep. 2017;7:44667.

42. Whidden LMJ, Rahimi S, Chaillet R, Chan D, Trasler JM. Compromised oocyte quality and assisted reproduction contribute to sex-specific effects on offspring outcomes and epigenetic patterning. Hum Mol Genet. 2016;25: 4649-60.

43. Kim GD, Ni J, Kelesoglu N, Roberts RJ, Pradhan S. Co-operation and communication between the human maintenance and de novo DNA (cytosine-5) methyltransferases. EMBO J. 2002;21:4183-95.

44. Li Z, Dai H, Martos SN, Xu B, Gao Y, Li T, Zhu G, Schones DE, Wang Z. Distinct roles of DNMT1-dependent and DNMT1-independent methylation patterns in the genome of mouse embryonic stem cells. Genome Biol. 2015;16:115.

45. Marchler-Bauer A, Derbyshire MK, Gonzales NR, Lu S, Chitsaz F, Geer LY, Geer RC, He J, Gwadz M, Hurwitz DI, et al. CDD: NCBl's conserved domain database. Nucleic Acids Res. 2015;43:D222-6.

46. Zhang ZM, Liu S, Lin K, Luo Y, Perry JJ, Wang Y, Song J. Crystal structure of human DNA methyltransferase 1. J Mol Biol. 2015;427:2520-31.

47. Song J, Rechkoblit O, Bestor TH, Patel DJ. Structure of DNMT1-DNA complex reveals a role for autoinhibition in maintenance DNA methylation. Science. 2011;331:1036-40.

48. Song J, Teplova M, Ishibe-Murakami S, Patel DJ. Structure-based mechanistic insights into DNMT1-mediated maintenance DNA methylation. Science. 2012;335:709-12.

49. Cheng X, Kumar S, Posfai J, Pflugrath JW, Roberts RJ. Crystal structure of the Hhal DNA methyltransferase complexed with S-adenosyl-L-methionine. Cell. 1993;74:299-307.

50. Klein CJ, Botuyan MV, Wu Y, Ward CJ, Nicholson GA, Hammans S, Hojo K, Yamanishi H, Karpf AR, Wallace DC, et al. Mutations in DNMT1 cause hereditary sensory neuropathy with dementia and hearing loss. Nat Genet. 2011:43:595-600.

51. McLaren W, Gil L, Hunt SE, Riat HS, Ritchie GRS, Thormann A, Flicek P, Cunningham F. The Ensembl variant effect predictor. Genome Biol. 2016;17:122.

52. Mackay DJ, Callaway JL, Marks SM, White HE, Acerini CL, Boonen SE, Dayanikli P, Firth HV, Goodship JA, Haemers AP, et al. Hypomethylation of multiple imprinted loci in individuals with transient neonatal diabetes is associated with mutations in ZFP57. Nat Genet. 2008:40:949-51.

53. Wilson M, Peters G, Bennetts B, McGillivray G, Wu ZH, Poon C, Algar E. The clinical phenotype of mosaicism for genome-wide paternal uniparental disomy: two new reports. Am J Med Genet A. 2008;146A: 137-48.

54. Rigby L, Muscat A, Ashley D, Algar E. Methods for the analysis of histone $\mathrm{H} 3$ and $\mathrm{H} 4$ acetylation in blood. Epigenetics. 2012;7:875-82.

55. Frauer $\mathrm{C}$, Leonhardt $\mathrm{H}$. A versatile non-radioactive assay for DNA methyltransferase activity and DNA binding. Nucleic Acids Res. 2009;37:e22.

56. Clarke GM, Anderson CA, Pettersson FH, Cardon LR, Morris AP, Zondervan KT. Basic statistical analysis in genetic case-control studies. Nat Protoc. 2011; 6:121-33. 